\title{
Internal electric fields and color shift in Cr3+-based gemstones
}

\author{
Aramburu, J. A.; Garcia-Fernandez, P.; García Lastra, Juan Maria; Barriuso, M. T.; Moreno, M.
}

Published in:

Physical Review B Condensed Matter

Link to article, DOI:

10.1103/PhysRevB.85.245118

Publication date:

2012

Document Version

Publisher's PDF, also known as Version of record

Link back to DTU Orbit

Citation (APA):

Aramburu, J. A., Garcia-Fernandez, P., García Lastra, J. M., Barriuso, M. T., \& Moreno, M. (2012). Internal electric fields and color shift in $\mathrm{Cr}{ }^{+}$-based gemstones. Physical Review B Condensed Matter, 85(24), 245118. https://doi.org/10.1103/PhysRevB3.85.245118

\section{General rights}

Copyright and moral rights for the publications made accessible in the public portal are retained by the authors and/or other copyright owners and it is a condition of accessing publications that users recognise and abide by the legal requirements associated with these rights.

- Users may download and print one copy of any publication from the public portal for the purpose of private study or research.

- You may not further distribute the material or use it for any profit-making activity or commercial gain

- You may freely distribute the URL identifying the publication in the public portal 


\title{
Internal electric fields and color shift in $\mathrm{Cr}^{3+}$-based gemstones
}

\author{
J. A. Aramburu, ${ }^{1}$ P. Garcia-Fernandez, ${ }^{1}$ J. M. García-Lastra, ${ }^{2}$ M. T. Barriuso, ${ }^{3}$ and M. Moreno ${ }^{1}$ \\ ${ }^{1}$ Departamento de Ciencias de la Tierra y Física de la Materia Condensada, Universidad de Cantabria, \\ Avenida de los Castros s/n, 39005 Santander, Spain \\ ${ }^{2}$ Center for Atomic-Scale Materials Design, Department of Physics, Technical University of Denmark, DK-2800 Kongens Lyngby, Denmark \\ ${ }^{3}$ Departamento de Física Moderna, Universidad de Cantabria, Avenida de los Castros s/n, 39005 Santander, Spain
}

(Received 16 February 2012; published 18 June 2012)

\begin{abstract}
Seeking to better understand the origin of the different colors of emerald and ruby, both $a b$ initio periodic and cluster calculations have been carried out. The calculations reproduce the interatomic distances measured for pure $\mathrm{Be}_{3} \mathrm{Si}_{6} \mathrm{Al}_{2} \mathrm{O}_{18}$ and $\mathrm{Al}_{2} \mathrm{O}_{3}$ as well as the $\mathrm{Cr}^{3+}-\mathrm{O}^{2-}$ distances in emerald and ruby. The mean $\mathrm{Cr}^{3+}-\mathrm{O}^{2-}$ distance for $\mathrm{Be}_{3} \mathrm{Si}_{6} \mathrm{Al}_{2} \mathrm{O}_{18}: \mathrm{Cr}^{3+}$ and $\mathrm{Al}_{2} \mathrm{O}_{3}: \mathrm{Cr}^{3+}$ is found to be practically equal to $1.97 \AA$, in agreement with recent experimental values. The present calculations confirm that the variations of optical properties due to $\mathrm{Cr}^{3+}$ impurities along the series of ionic oxides can be understood merely through the $\mathrm{CrO}_{6}{ }^{9-}$ unit but subject to the electric field due to the rest of the lattice ions. As a salient feature it is proved that changes in electronic density and covalency due to the internal field are not the cause of the color shift. Therefore, the red color of ruby is not due to the polarization of the electronic cloud around chromium as a result of the $\mathrm{C}_{3}$ local symmetry. The present study also demonstrates that the variation of the ligand field splitting parameter, 10Dq, induced by the internal electric field comes mainly from the contributions of first shells of ions around the $\mathrm{CrO}_{6}{ }^{9-}$ unit. As a consequence, $10 \mathrm{Dq}$ in emerald is not influenced by the internal field, as the contribution from $\mathrm{Be}^{2+}$ first neighbors is practically compensated by that of $\mathrm{Si}^{4+}$ second neighbors. In contrast, in ruby the $t_{2 g}$ levels are shifted by the internal field $0.24 \mathrm{eV}$ more than the $e_{g}$ ones, so explaining the color shift in this gemstone in comparison with emerald. This result is shown to arise partially from the asymmetric form of the internal electrostatic potential along the $C_{3}$ axis in $\mathrm{Al}_{2} \mathrm{O}_{3}$.
\end{abstract}

DOI: 10.1103/PhysRevB.85.245118 PACS number(s): 71.55.-i, 71.15.Mb, 78.40.-q, 91.60.Mk

\section{INTRODUCTION}

The properties of oxides doped with $\mathrm{Cr}^{3+}$ ions, like ruby $\left(\mathrm{Al}_{2} \mathrm{O}_{3}: \mathrm{Cr}^{3+}\right)$, emerald $\left(\mathrm{Be}_{3} \mathrm{Si}_{6} \mathrm{Al}_{2} \mathrm{O}_{18}: \mathrm{Cr}^{3+}\right)$, or alexandrite $\left(\mathrm{BeAl}_{2} \mathrm{O}_{4}: \mathrm{Cr}^{3+}\right)$, have raised a great deal of interest. ${ }^{1-22}$ Despite that in all oxides the $\mathrm{Cr}^{3+}$ impurity is surrounded by an octahedron of oxygen ligands, the color exhibited by gemstones like ruby and emerald, however, is not the same. ${ }^{3,6}$ Historically, two main assumptions have been put forward for explaining such a difference. On one hand, some scientists have assumed that the mean $\mathrm{Cr}^{3+}-\mathrm{O}^{2-}$ distance, $R$, is not the same for gemstones like ruby and emerald. ${ }^{1,3,4,6,7,10,15,23}$ This idea relies on the fact that color is mainly determined by the energy of the ${ }^{4} A_{2}\left(t_{2 g}^{3}\right) \rightarrow{ }^{4} T_{2}\left(t_{2 g}^{2} e_{g}{ }^{1}\right)$ spin allowed transition which is equal to the ligand field splitting parameter $10 \mathrm{Dq} .{ }^{24}$ Moreover, $10 \mathrm{Dq}$ is known to be very sensitive to hydrostatic pressures and thus to changes of the metal-ligand distance. ${ }^{25,26}$

By contrast, many other authors have suggested that unpaired electrons are not fully localized on the $\mathrm{CrO}_{6}{ }^{9-}$ complex as they are also present in the second and further coordination spheres, which are not the same in ruby and emerald..$^{2,27-29}$ According to this view the flow of electronic charge outside the $\mathrm{CrO}_{6}{ }^{9-}$ complex would be responsible for the different $10 \mathrm{Dq}$ value exhibited by gemstones like ruby and emerald.

Nevertheless, with regard to the first tentative explanation, accurate extended x-ray absorption fine structure (EXAFS) results carried out on ruby and emerald have proved that the mean $\mathrm{Cr}^{3+}-\mathrm{O}^{2-}$ distance is the same within the experimental uncertainty of 1 pm. ${ }^{9,13}$ Moreover, a significant presence of unpaired electrons beyond the first coordination sphere is not supported by electron nuclear double resonance (ENDOR) results obtained on ionic lattices like $\mathrm{Al}_{2} \mathrm{O}_{3}$ doped with
$\mathrm{Cr}^{3+} \cdot{ }^{30,31} \mathrm{Ab}$ initio calculations carried out on transition metal impurities in ionic lattices are consistent with this view. ${ }^{32,33}$

Bearing in mind these facts, recent results on $\mathrm{Cr}^{3+}$-doped different fluoride and oxide lattices have shown that the observed differences in absorption and emission spectra can all be understood by just considering the internal electric field, $\mathbf{E}_{R}(\mathbf{r})$, created by the rest of lattice ions upon the $\mathrm{CrF}_{6}{ }^{3-}$ or $\mathrm{CrO}_{6}{ }^{9-}$ complex, respectively, where active electrons are confined. ${ }^{34}$ This internal field is generated by the corresponding electrostatic potential, $V_{R}(\mathbf{r})$, through $\mathbf{E}_{R}(\mathbf{r})=-\nabla V_{R}(\mathbf{r})$. Obviously, covalency in the complex is influenced by such an internal field, although unpaired electrons are not flowing outside the complex. As insulating lattices like $\mathrm{Al}_{2} \mathrm{O}_{3}, \mathrm{Be}_{3} \mathrm{Si}_{6} \mathrm{Al}_{2} \mathrm{O}_{18}, \mathrm{BeAl}_{2} \mathrm{O}_{4}$ or $\mathrm{MgAl}_{2} \mathrm{O}_{4}$ are not isomorphous, ${ }^{9,13,14,35-38}$ the different shape of $\mathbf{E}_{R}(\mathbf{r})$ has been shown to be greatly responsible for the different color due to substitutional $\mathrm{Cr}^{3+}$ impurities in such lattices. ${ }^{11,12,17}$ Also the distinct optical and magnetic properties exhibited by transition-metal impurities in the normal perovskite $\mathrm{KMgF}_{3}$ and in the inverted perovskite $\mathrm{LiBaF}_{3}$ have been accounted for through the same mechanism. ${ }^{32,34}$ Furthermore, it has been shown that $\mathbf{E}_{R}(\mathbf{r})$ plays a key role for understanding the local structure and the associated spectroscopic properties of $\mathrm{Cu}^{2+}$ - and $\mathrm{Cr}^{3+}$-doped layered perovskites such as $\mathrm{K}_{2} A \mathrm{~F}_{4}$ ( $A=\mathrm{Mg}, \mathrm{Zn}){ }^{39}$

Despite that the mere addition of the internal electric field $\mathbf{E}_{R}(\mathbf{r})$ to the $\mathrm{CrO}_{6}{ }^{9-}$ complex allows one to understand an important number of experimental facts corresponding to the $\mathrm{Cr}^{3+}$-based gemstones, there is, however, a fundamental question which needs to be answered. As it has been pointed out, the internal electric field $\mathbf{E}_{R}(\mathbf{r})$ will modify the electronic density 
and covalency inside the $\mathrm{CrO}_{6}{ }^{9-}$ unit provided $V_{R}(\mathbf{r})$ is not a constant on the whole complex region. This conclusion follows directly from the Hohenberg-Kohn theorem. ${ }^{40}$ Therefore, it is of fundamental importance to clarify whether such changes of electronic density are or are not directly related to the changes in $10 \mathrm{Dq}$ which are in turn responsible for the color shift. This work is addressed to shed light on this relevant matter.

For achieving this goal, we have first explored two representative gemstones as ruby and emerald by means of $a b$ initio calculations. Aside from deriving the equilibrium $\mathrm{Cr}^{3+}-\mathrm{O}^{2-}$ distances and the 10Dq value for both gemstones, particular attention is paid to look into the actual changes of electronic levels and the electronic density induced by $V_{R}(\mathbf{r})$. Bearing these results in mind, we investigate in a further step a model system where $V_{R}(\mathbf{r})$ keeps the cubic symmetry, thus making the analysis of results easier than for ruby or emerald where the local symmetry is $C_{3}$ and $D_{3}$, respectively.

This work is arranged as follows. As the present study is based on electron localization, the main facts supporting its validity are briefly reviewed in Sec. II. Relevant details of the employed $a b$ initio methods are given in Sec. III. In Sec. IV the changes in electronic density due to the internal field $\mathbf{E}_{R}(\mathbf{r})$ for ruby and emerald are quantified. Section $\mathrm{V}$ is addressed to quantify the shift in 10Dq parameter directly associated with electronic density changes in the case of the model system. Some final remarks are presented in the last section.

\section{ELECTRON LOCALIZATION}

It is well known that the crystal field spectra of pure compounds like $\mathrm{Cr}_{2} \mathrm{O}_{3}$ or $\mathrm{KNiF}_{3}$ look rather similar to those observed for $\mathrm{Al}_{2} \mathrm{O}_{3}: \mathrm{Cr}^{3+}$ or $\mathrm{KMgF}_{3}: \mathrm{Ni}^{2+} .2,24,26$ This fact strongly supports that in all these systems active electrons are essentially localized in the $M X_{6}{ }^{\mathrm{q}-}$ complex $\left(M=\mathrm{Cr}^{3+}, \mathrm{Ni}^{2+}\right)$ formed with the six $X$ ligands $(X=\mathrm{O}, \mathrm{F})$. This conclusion is consistent with a general view by W. Kohn stressing that electron localization in the ground state is the fingerprint of every insulating material. ${ }^{41-43}$

Relevant experimental information on the degree of localization for impurities in insulating lattices is obtained from the ENDOR technique. For instance, in $\mathrm{KMgF}_{3}: \mathrm{Mn}^{2+}$, in addition to the average hyperfine constant for ligands $A_{s}(1)$, the ENDOR technique allows one to measure the corresponding constant $\mathrm{A}_{\mathrm{s}}(2)$ for the nearest $\mathrm{F}^{-}$ions lying outside the $\mathrm{MnF}_{6}{ }^{4-}$ complex. ${ }^{44}$ The values $A_{\mathrm{s}}(1)=54 \mathrm{MHz}$ and $\mathrm{A}_{\mathrm{s}}(2)=0.64 \mathrm{MHz}$ thus support that active electrons are basically localized on the $\mathrm{MnF}_{6}{ }^{4-}$ unit. In the case of systems like $\mathrm{Al}_{2} \mathrm{O}_{3}: \mathrm{Cr}^{3+}$ there is no hyperfine interaction with ligands because the nuclear spin of the ${ }^{16} \mathrm{O}$ isotope is zero. However, the hyperfine interaction with the closest aluminum ions has been measured by ENDOR, obtaining an isotropic hyperfine constant $\mathrm{A}_{\mathrm{s}}(\mathrm{Al})$ at around $2 \mathrm{MHz}^{30}$ Bearing in mind that an electron placed on the $3 s$ orbital of free aluminum leads to a hyperfine constant $\mathrm{A}_{\mathrm{s}}^{0}=3920 \mathrm{MHz},{ }^{45}$ the ratio $\mathrm{A}_{\mathrm{s}}(\mathrm{Al}) / \mathrm{A}_{\mathrm{s}}^{0}$ implies that only a charge of the order of $5 \times 10^{-4} e$ has been transferred from the $\mathrm{CrO}_{6}{ }^{9-}$ unit to a close aluminum ion. ENDOR results on $\mathrm{MgAl}_{2} \mathrm{O}_{4}: \mathrm{Cr}^{3+}, 31$ or $\mathrm{RbCdF}_{3}: \mathrm{Cr}^{3+}$ (Ref. 46) also show that the charge of active electrons is essentially confined in the complex formed by the impurity and its six nearest neighbors. A similar conclusion has been obtained from ab initio calculations carried out on big clusters where $\mathrm{CrF}_{6}{ }^{3-}$ unit is embedded. ${ }^{33}$

\section{COMPUTATIONAL DETAILS}

In a first step, periodic ab initio calculations based on the density functional theory (DFT) have been carried out on ruby and emerald in order to obtain the equilibrium geometries around the $\mathrm{Cr}^{3+}$ impurities in both gemstones as well as values of the charges of the lattice ions. Calculations were performed with the CRYSTAL09 package that employs localized Gaussian basis sets to represent the Bloch orbitals. ${ }^{47}$ All ions have been described by all-electron basis sets of reasonably high quality (5-11G for Be, 8-411G* for O, 85-11G for A1, 88-31G* for $\mathrm{Si}$, and $86-411 \mathrm{G}^{* *}$ for $\mathrm{Cr}$ ) taken from the CRYSTAL data base. ${ }^{48}$ In the case of emerald we have used the hexagonal cell of $\mathrm{Be}_{3} \mathrm{Si}_{6} \mathrm{Al}_{2} \mathrm{O}_{18}$ with 58 ions, where the $\mathrm{Cr}^{3+}$ replaces an $\mathrm{Al}^{3+}$ ion of the lattice, while for ruby we used a $2 \times$ $2 \times 2$ supercell with 80 atoms. We have treated the exchange and correlation of the electrons through the B1WC hybrid functional ${ }^{49}$ that allows geometry and band gaps to be obtained with great accuracy and reliability not requiring the input of any semiempirical parameter by the user. For checking the reliability of the employed method the equilibrium geometries of pure $\mathrm{Al}_{2} \mathrm{O}_{3}$ and $\mathrm{Be}_{3} \mathrm{Si}_{6} \mathrm{Al}_{2} \mathrm{O}_{18}$ lattices have also been calculated.

In a second step, molecular DFT calculations have been carried out on $\mathrm{CrO}_{6}{ }^{9-}$ complexes either isolated or merely subject to the electric field $\mathbf{E}_{R}(\mathbf{r})$ generated by infinite point charges from the rest of the lattice. In all these cases the $\mathrm{Cr}^{3+}-\mathrm{O}^{2-}$ distances correspond to the actual values for ruby and emerald. As it has been discussed in the previous section, the great localization of the electrons of the impurity makes that this simple $\mathrm{CrO}_{6}{ }^{9-}$ unit, but subject to the electric field $\mathbf{E}_{R}(\mathbf{r})$, it is enough to unveil the microscopic origin of the different optical properties displayed by $\mathrm{Cr}^{3+}$ in a series of oxides or fluorides. ${ }^{11,12,17,34}$ Calculations have been performed by means of the ADF 2010.02 code. ${ }^{50}$ The generalized gradient approximation (GGA) exchange-correlation energy was computed according to the Perdew-Wang-91 functional. ${ }^{51}$ The core electrons $(1 s-3 p$ for $\mathrm{Cr}$ and $1 s$ for $\mathrm{O})$ were kept frozen. Chromium ion was described through the basis sets of TZP quality [triple- $\xi$ Slater-type orbital (STO) plus one polarization function], whereas a DZP basis set (double- $\xi$ STO plus one polarization function) was used for oxygen ions. It has been reported in previous works ${ }^{11,12,52}$ that in order to correctly represent the metal-ligand covalence in a cluster model it is necessary to use a smaller basis set size in the ligands than in the metal. For being sure about the reliability of our main conclusions, calculations with other basis sets and functionals have also been performed. As a salient feature the main effect introduced by $\mathbf{E}_{R}(\mathbf{r})$ on $10 \mathrm{Dq}$ is always found for every employed basis set or exchange-correlation functional. It is worth noting that calculated properties are found to be less dependent on the basis set using DFT than traditional methods based on the Hartree-Fock description. ${ }^{53,54} 10 \mathrm{Dq}$ has always been calculated following the average of configuration procedure given in Ref. 55. The center of gravity of the small splitting undergone by the $t_{2 g}$ orbital under the trigonal site symmetry has been taken into account when deriving $10 \mathrm{Dq}$. 
In particular, assuming that $10 \mathrm{Dq} \propto R^{-n}$, an exponent $n=4.2$ has been found by means of these calculations. This figure is not far from the value $n=4.5$ measured experimentally for ruby under hydrostatic pressure. ${ }^{5}$ The electrostatic potential $V_{R}(\mathbf{r})$ coming from all ions of $\mathrm{Al}_{2} \mathrm{O}_{3}$ or $\mathrm{Be}_{3} \mathrm{Si}_{6} \mathrm{Al}_{2} \mathrm{O}_{18}$ crystals lying outside the $\mathrm{CrO}_{6}{ }^{9-}$ unit has been calculated by means of the Ewald method, following the procedure described in Ref. 56. The nominal ionic charges were employed in these calculations since our periodic calculations performed on $\mathrm{Al}_{2} \mathrm{O}_{3}$ and $\mathrm{Be}_{3} \mathrm{Si}_{6} \mathrm{Al}_{2} \mathrm{O}_{18}$ lattices have demonstrated that the total charges on oxygen, aluminum, beryllium, and silicon ions are practically equal to $-2 e,+3 e,+2 e$, and $+4 e(e=$ proton charge), respectively, pointing out that bonding is highly ionic indeed. A similar conclusion was previously reached by Sousa et al. in their study of $\mathrm{Al}_{2} \mathrm{O}_{3} .{ }^{57}$

\section{RESULTS FOR RUBY AND EMERALD}

\section{A. Ruby}

The structure of the $\mathrm{Al}_{2} \mathrm{O}_{3}$ host lattice ${ }^{9,36}$ is depicted on Fig. 1. A given $\mathrm{Al}^{3+}$ cation is surrounded by six $\mathrm{O}^{2-}$ anions, three at a short distance $R_{\mathrm{s}}=1.857 \AA$ and the rest lying further at $R_{1}=1.969 \AA$. The local symmetry is $C_{3}$. Along the $C_{3}$ axis there are two $\mathrm{Al}^{3+}$ ions neighbors of a given aluminum ion. One called $\mathrm{Al}_{\mathrm{s}}^{3+}$ is located at $2.65 \AA$, while the other called $\mathrm{Al}_{1}^{3+}$ is placed much further at $3.80 \AA$. In the plane perpendicular to the $C_{3}$ axis there are three $\mathrm{Al}^{3+}$ ions lying at $2.79 \AA$. Such ions are called $\mathrm{Al}_{\perp}^{3+}$ in Fig. 1 .

The formation of ruby implies the $\mathrm{Al}^{3+} \rightarrow \mathrm{Cr}^{3+}$ substitution. Due to the different ionic radius of $\mathrm{Al}^{3+}$ and $\mathrm{Cr}^{3+}$, this replacement is likely to modify the values of both $R_{\mathrm{s}}$ and $R_{1}$ distances. The next section is focused on the actual $R_{\mathrm{S}}$ and $R_{1}$ values when an $\mathrm{Al}^{3+}$ ion is replaced by $\mathrm{Cr}^{3+}$, as they are important for a right interpretation of optical data of ruby.

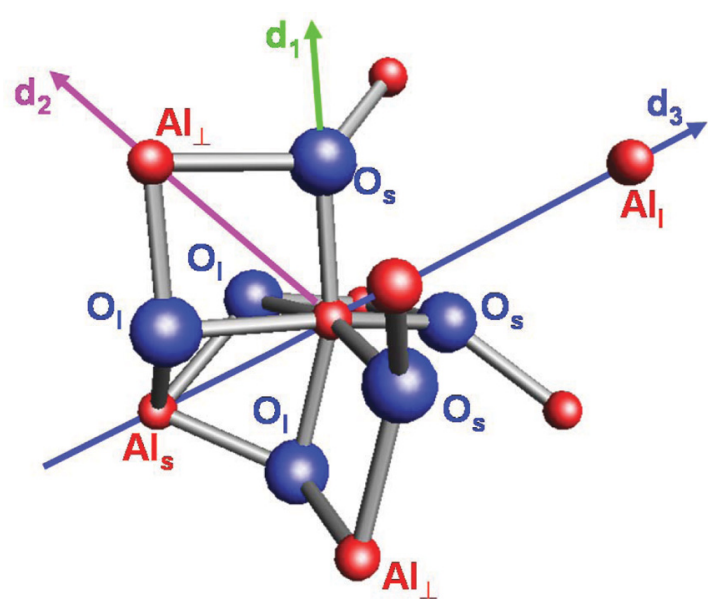

FIG. 1. (Color online) Local structure of corundum $\mathrm{Al}_{2} \mathrm{O}_{3}$ around an $\mathrm{Al}^{3+}$ ion with a $C_{3}$ symmetry. A given $\mathrm{Al}^{3+}$ cation is surrounded by six $\mathrm{O}^{2-}$ anions, three $\mathrm{O}_{\mathrm{s}}$ at a short distance $R_{\mathrm{s}}=1.857 \AA$ and three $\mathrm{O}_{\mathrm{s}}$ lying further at $R_{\mathrm{l}}=1.969 \AA$. Along the $C_{3}$ axis there are two $\mathrm{Al}^{3+}$ ions neighbors of a given aluminum ion, one called $\mathrm{Al}_{\mathrm{s}}^{3+}$ is located at $2.65 \AA$ while the other called $\mathrm{Al}_{1}^{3+}$ is placed much further at $3.80 \AA$. In the plane perpendicular to the $C_{3}$ axis there are three $\mathrm{Al}_{\perp}^{3+}$ ions lying at $2.79 \AA$.
TABLE I. Values of $R_{\mathrm{s}}$ and $R_{\mathrm{l}}$ distances (in angstroms) obtained in this work by means of periodic calculations for pure $\mathrm{Al}_{2} \mathrm{O}_{3}$. The values are compared to experimental data, ${ }^{9,36}$ as well as to those previously calculated by Duan et al..$^{58}$ and Mazurenko et al. ${ }^{59}$

\begin{tabular}{lcccc}
\hline \hline & Present work & Duan et al. & Mazurenko et al. & Experimental \\
\hline$R_{\mathrm{S}}(\AA)$ & 1.868 & 1.839 & 1.85 & 1.857 \\
$R_{\mathrm{l}}(\AA)$ & 1.976 & 1.969 & 1.98 & 1.969 \\
\hline \hline
\end{tabular}

\section{Local structure in ruby}

As a first step we have derived by means of periodic calculations the $R_{\mathrm{S}}$ and $R_{1}$ values corresponding to the pure $\mathrm{Al}_{2} \mathrm{O}_{3}$ lattice. As shown in Table I the figures $R_{\mathrm{s}}=1.868 \AA$ and $R_{1}=1.976 \AA$ are close to those previously obtained by Douan $^{58}$ and coincident within $1 \mathrm{pm}$ with the experimental values $R_{\mathrm{s}}=1.857 \AA$ and $R_{1}=1.969 \AA .{ }^{9,36}$

The calculated equilibrium $R_{\mathrm{S}}$ and $R_{1}$ distances corresponding to ruby are given in Table II where they are compared to the experimental EXAFS values obtained by Gaudry et al., ${ }^{9}$ as well as to figures derived in previous calculations. Values found in the present calculations are reasonably close to the experimental figures $R_{\mathrm{s}}=1.92 \pm 0.01 \AA$ and $R_{1}=2.01 \pm 0.01 \AA$ and support that the mean $\mathrm{Cr}^{3+}-\mathrm{O}^{2-}$ distance in ruby is $R_{\mathrm{av}}=1.97 \AA$, which is thus identical to that measured for emerald. ${ }^{13}$ It can also be seen in Table I that the metal-ligand distance values obtained in our calculations are very similar to those computed by other authors on the same 80-atom supercell but using different. However, unlike with previous calculations, all our calculations have been made using all-electron basis functions and hybrid functionals.

\section{Effect of the internal electric field on $10 D q$}

The form of the electrostatic potential due to the rest of the lattice ions on the $\mathrm{CrO}_{6}{ }^{9-}$ complex $V_{R}(\mathbf{r})$ for three particular directions in ruby is depicted in Fig. 2. So, the changes of $V_{R}(\mathbf{r})$ along the $\mathrm{O}_{\mathrm{s}}-\mathrm{Cr}-\mathrm{O}_{1}$ path (direction $d_{1}$ ), the diagonal joining the central $\mathrm{Cr}^{3+}$ impurity, one $\mathrm{Al}_{\perp}^{3+}$ cation (direction $d_{2}$ ), and finally the $C_{3}$ axis (direction $d_{3}$ ) are all shown in Fig. 2.

As portrayed in Fig. 2, there is an electric field directed along the trigonal axis at the chromium site, a fact consistent with the $C_{3}$ local symmetry. Figure 2 also indicates that if unpaired electrons would be rigorously placed at the position of the chromium nucleus, its energy would experience a decrease of about $-54 \mathrm{eV}$ due to the action of $(-e) V_{R}(0)$. However, if the unpaired electronic density spreads on the $\mathrm{CrO}_{6}{ }^{9-}$ complex, $V_{R}(\mathbf{r})$ changes significantly in that region, as shown in Fig. 2. For instance, if $\mathbf{r}$ is varied along direction $d_{3}$, then $(-e) V_{R}(\mathbf{r})=-85 \mathrm{eV}$ when $|\mathbf{r}|=2 \AA$ and the electron is close to $\mathrm{Al}_{\mathrm{s}}{ }^{3+}$, while $(-e) V_{R}(\mathbf{r})=-45 \mathrm{eV}$ when it is at the same distance but in the opposite direction.

As shown in Fig. 3, the energy decrease induced by $(-e) V_{\mathrm{R}}(\mathbf{r})$ is different for $t_{2 g}$ and $e_{g}$ antibonding orbitals. In fact, while the center of the gravity of $e_{g}$ levels moves downward by $52.22 \mathrm{eV}$, this figure is slightly higher $(52.48 \mathrm{eV})$ for the case of $t_{2 g}$ levels, such as depicted in Fig. 3. This difference, though tiny, produces an increase in the $10 \mathrm{Dq}$ value. Indeed, if $10 \mathrm{Dq}$ is calculated for the isolated $\mathrm{CrO}_{6}{ }^{9-}$ complex at the right equilibrium geometry in ruby but ignoring the effects of 
TABLE II. Values of $\mathrm{Cr}^{3+}-\mathrm{O}^{2-}$ distances calculated by means of periodic calculations using an 80 -atom supercell for $\mathrm{Al}_{2} \mathrm{O}_{3}: \mathrm{Cr}^{3+}$. $\mathrm{The}$ $R_{\mathrm{l}}$ and $R_{\mathrm{s}}$ distances are compared to those measured by EXAFS (Ref. 9) and those derived by Duan et al..$^{58}$ and Gaudry et al. ${ }^{9}$ through LDA Carr-Parinello methods, Mazurenko et al. ${ }^{59}$ with a LDA + U tight-binding linear-muffin-tin method, and Watanabe et al. ${ }^{18}$ with a GGA calculation.

\begin{tabular}{lcccccr}
\hline \hline & \multicolumn{5}{c}{ Calculated } \\
\cline { 2 - 6 } & Present work & Duan et al. & Gaudry et al. & Mazurenko et al. & Watanabe et al. & Experimental \\
\hline$R_{\mathrm{s}}(\AA)$ & 1.942 & 1.918 & 1.95 & 1.93 & 1.922 & 1.92 \\
$R_{\mathrm{l}}(\AA)$ & 1.997 & 2.018 & 2.00 & 1.99 & 1.986 & 2.01 \\
\hline \hline
\end{tabular}

$V_{R}(\mathbf{r})$, a value of $10 \mathrm{Dq}=2.00 \mathrm{eV}$ is obtained (Fig. 3), which is smaller than the experimental figure $10 \mathrm{Dq}=2.24 \mathrm{eV}^{3,6}$ Nevertheless, as shown in Fig. 3, the action of $(-e) V_{R}(\mathbf{r})$ on the $\mathrm{CrO}_{6}{ }^{9-}$ complex produces an increase of $10 \mathrm{Dq}$ of $0.24 \mathrm{eV}$ that although small (12\%), shifts the color of ruby from green to red. This conclusion is thus fully consistent with the results of a previous study. ${ }^{11}$ Supporting this view a calculation carried out on a bigger $\mathrm{CrO}_{6} \mathrm{Al}_{7}{ }^{9+}$ cluster including the electric field due to the rest of the ions of the $\mathrm{Al}_{2} \mathrm{O}_{3}$ lattice gives a value of $10 \mathrm{Dq}=2.18 \mathrm{eV}$.

\section{Changes of electronic density due to the internal electric field}

The variations of charge distribution in the $t_{2 g}$ and $e_{g}$ antibonding orbitals induced by the internal field of ruby upon the $\mathrm{CrO}_{6}{ }^{9-}$ unit are displayed in Table III. Results given in this table correspond to the ${ }^{4} A_{2}\left(t_{2 g}^{3}\right)$ ground state at the experimental equilibrium geometry of the $\mathrm{CrO}_{6}{ }^{9-}$ complex in ruby. In that state $t_{2 g}$ levels are half filled while the two $e_{g}$ levels are unoccupied. Very close results to those reported in Table III are obtained for the average $t_{2 g}^{3 / 5} e_{g}^{2 / 5}$ configuration.

The values gathered in Table III show that the internal electric field $\mathbf{E}_{R}(\mathbf{r})$ in ruby does not produce drastic changes on the electronic density for both $t_{2 g}$ and $e_{g}$ antibonding levels. Indeed, the changes on the $3 d(\mathrm{Cr})$ charge induced by the addition of $\mathbf{E}_{R}(\mathbf{r})$ are smaller than $4 \%$ for the two kinds of levels.

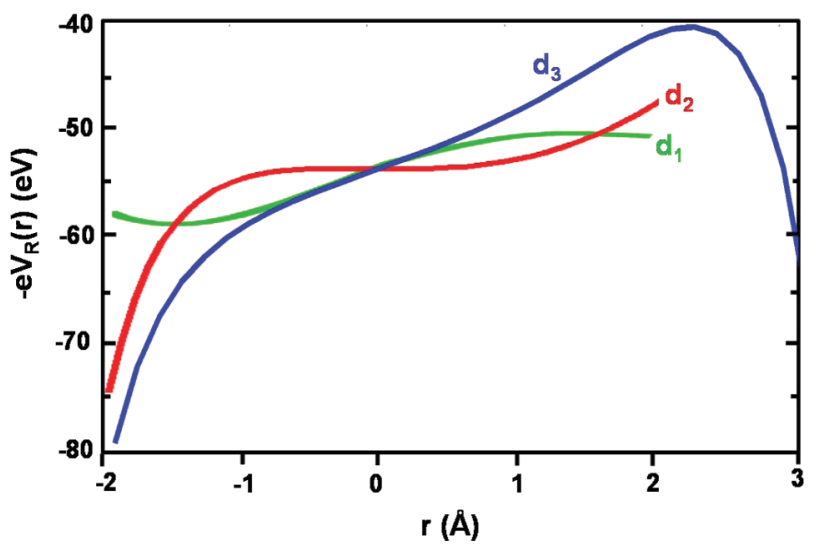

FIG. 2. (Color online) Potential energy on an electron, $(-e) V_{R}(\mathbf{r})$, due to the internal electric potential, $V_{R}(\mathbf{r})$, produced by the rest of the lattice ions of ruby on the $\mathrm{CrO}_{6}^{9-}$ complex. Energy is depicted along the $\mathrm{O}_{\mathrm{s}}-\mathrm{Cr}-\mathrm{O}_{1}$ path (direction $d_{1}$ ), the diagonal joining the central $\mathrm{Cr}^{3+}$ impurity, and one $\mathrm{Al}_{\perp}^{3+}$ cation (direction $d_{2}$ ) and the $C_{3}$ axis (direction $d_{3}$ ).
It can be noticed that in the antibonding $e_{g}$ level the unpaired electron spends more time on $\mathrm{O}_{\mathrm{s}}$ than on $\mathrm{O}_{1}$ oxygens. As the opposite happens for the corresponding bonding orbital which is fully occupied, this implies that there is a net flow of electronic charge going from $\mathrm{O}_{\mathrm{s}}$ to $\mathrm{O}_{1}$. This fact, similar to that discussed in $\mathrm{LiBaF}_{3}: \mathrm{Mn}^{2+}, 32$ is consistent with the closeness of $\mathrm{Al}_{\mathrm{S}}{ }^{3+}$ to the three $\mathrm{O}_{\mathrm{l}}$ ligands (Fig. 1) and the form of $(-e) V_{R}(\mathbf{r})$ along the $d_{1}$ direction, such as it is shown in Fig. 2.

\section{B. Emerald}

\section{Local structure in emerald}

The structure of beryl $\left(\mathrm{Be}_{3} \mathrm{Si}_{6} \mathrm{Al}_{2} \mathrm{O}_{18}\right)$ around an $\mathrm{Al}^{3+}$ ion is shown in Fig. 4. ${ }^{13,37,38}$ The local symmetry is $D_{3}$, higher than in ruby, and all nearest $\mathrm{O}^{2-}$ anions lie at the same distance $R=1.903 \AA$, as shown in Table IV.Thus, this value is only $0.01 \AA$ smaller than the average $\mathrm{Al}^{3+}-\mathrm{O}^{2-}$ distance measured in $\mathrm{Al}_{2} \mathrm{O}_{3}$.

Results on the equilibrium geometry of beryl derived through periodic calculations are also collected in Table IV together with previous data obtained by Gaudry et al. ${ }^{13}$ It can be noticed that all calculated $R$ values gathered in Table IV are coincident with the experimental values within $0.4 \%$. Similarly the experimental distances between an $\mathrm{Al}^{3+}$ ion and the three nearest $\mathrm{Be}^{2+}$ ions $(2.66 \AA)$ and the six closest $\mathrm{Si}^{4+}$ ions (3.26 $\AA$ ) are reasonably reproduced by the calculations.

The replacement of an $\mathrm{Al}^{3+}$ by a $\mathrm{Cr}^{3+}$ impurity induces, as expected, a slightly outward relaxation, such as shown in Table $\mathrm{V}$. The $\mathrm{Cr}^{3+}-\mathrm{O}^{2-}$ distance derived by the present calculations $(R=1.968 \AA)$ is coincident within $0.4 \%$ with

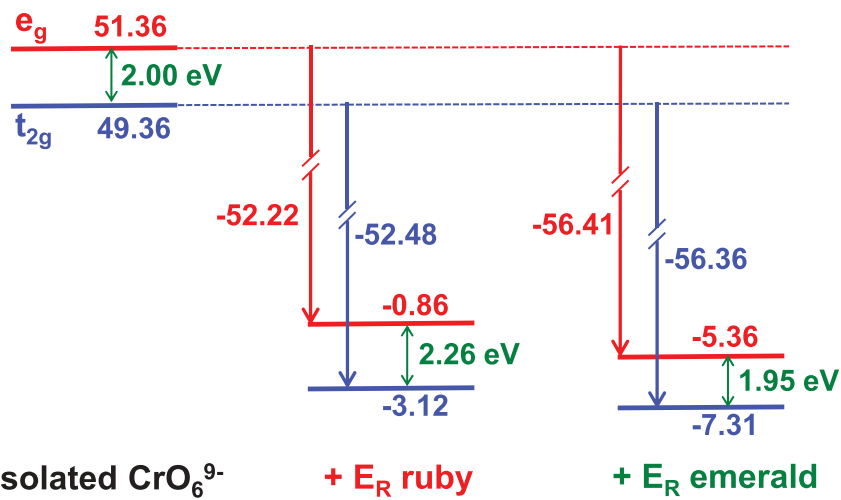

FIG. 3. (Color online) Scheme depicting the energy decrease induced by the $(-e) V_{R}(\mathbf{r})$ contribution for $t_{2 g}$ and $e_{g}$ antibonding orbitals in ruby and emerald. 
TABLE III. Mulliken populations (in percent) for antibonding $e_{g}$ (first row) and $t_{2 g}$ (second row) levels of ruby derived from the present calculations for the ${ }^{4} A_{2}\left(t_{2 g}^{3}\right)$ ground state of a $\mathrm{CrO}_{6}^{9-}$ complex at the experimental equilibrium geometry. Results obtained for the isolated $\mathrm{CrO}_{6}^{9-}$ complex are compared with those derived taking into account the internal field $\mathbf{E}_{R}(\mathbf{r})$. Only the electronic charge lying on the $3 d$ orbitals of chromium as well as that on $2 p$ and $2 s$ orbitals of three $\mathrm{O}_{1}$ and three $\mathrm{O}_{\mathrm{s}}$ ligand ions is given. Due to the $C_{3}$ symmetry, the values given in this table mean an average value of three orbitals emerging from $t_{2 g}$ under strict cubic symmetry. Note that in ${ }^{4} A_{2}\left(t_{2 g}^{3}\right)$ ground state the antibonding $e_{g}$ levels are unoccupied while they are partially occupied in the excited ${ }^{4} T_{2}\left(t_{2 g}^{2} e_{g}^{1}\right)$ state placed an energy 10Dq above the ground state. ${ }^{24}$

\begin{tabular}{lcrrcc}
\hline \hline & $\mathrm{Cr}(3 d)$ & $2 p\left(\mathrm{O}_{1}\right)$ & $2 p\left(\mathrm{O}_{\mathrm{s}}\right)$ & $2 s\left(\mathrm{O}_{\mathrm{l}}\right)$ & $2 s\left(\mathrm{O}_{\mathrm{s}}\right)$ \\
\hline Isolated $\mathrm{CrO}_{6}^{9-}$ & 77.62 & 11.00 & 8.32 & 1.12 & 1.44 \\
& 86.00 & 4.61 & 7.86 & - & - \\
With $\mathbf{E}_{R}(\mathbf{r})$ & 76.06 & 10.41 & 11.82 & 0.83 & 1.40 \\
& 89.40 & 3.15 & 6.05 & - & - \\
\hline \hline
\end{tabular}

the experimental value reported by Gaudry et $a l .^{13}$ and is thus essentially coincident with the average $\mathrm{Cr}^{3+}-\mathrm{O}^{2-}$ distance determined for ruby (Table II).

\section{Influence of the internal electric field in emerald}

The form of $(-e) V_{R}(\mathbf{r})$ energy for some particular directions in emerald is depicted in Fig. 5, where $d_{1}, d_{2}, d_{3}$, and $d_{4}$ directions correspond, respectively, to a $\mathrm{O}-\mathrm{Cr}-\mathrm{O}$ path joining two opposite oxygens, a $C_{2}$ axis joining $\mathrm{Cr}^{3+}$ with a close $\mathrm{Be}^{2+}$, and the $C_{3}$ axis and a path bisecting a O-Cr-O angle involving two adjacent oxygen ions which does not intersect a close $\mathrm{Be}^{2+}$ ion (Fig. 4). As it can be seen in Fig. 5, there is no electric field at the chromium site, a result consistent with the $D_{3}$ symmetry for emerald. Similarly to the case of ruby, $(-e) V_{R}(0) \approx-54 \mathrm{eV}$. Nevertheless, the values of $(-e)\left|V_{R}(\mathbf{r})-V_{R}(0)\right|$ for $|\mathbf{r}| \leqslant 2 \AA$ are, in general, smaller than

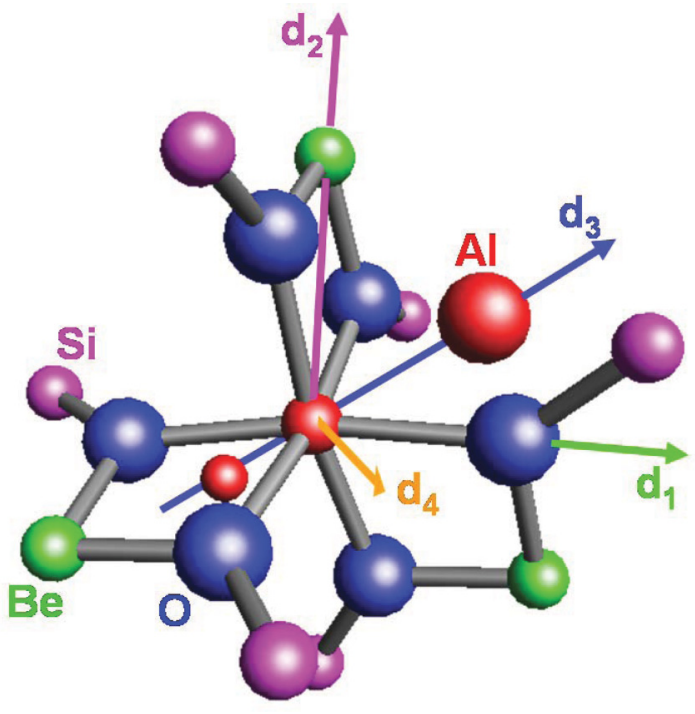

FIG. 4. (Color online) Local structure of beryl $\left(\mathrm{Be}_{3} \mathrm{Si}_{6} \mathrm{Al}_{2} \mathrm{O}_{18}\right)$ around an $\mathrm{Al}^{3+}$ ion with a $\mathrm{D}_{3}$ symmetry. All nearest $\mathrm{O}^{2-}$ anions lie at the same distance $R=1.903 \AA$.
TABLE IV. Structural parameters (all in angstrom) of pure beryl $\left(\mathrm{Be}_{3} \mathrm{Si}_{6} \mathrm{Al}_{2} \mathrm{O}_{18}\right)$ derived from the present periodic calculations. Aside from the lattice parameters $a$ and $c$, the distances between an $\mathrm{Al}^{3+}$ ion and its nearest $\mathrm{O}^{2-}, \mathrm{Be}^{2+}$, and $\mathrm{Si}^{4+}$ ions are reported. These values are compared to experimental figures derived by Gibbs et al. ${ }^{37}$ as well as to the values of Al-O, Al-Be, and Al-Si distances obtained by Gaudry et al. ${ }^{13}$ through periodic Carr-Parinello calculations.

\begin{tabular}{lccc}
\hline \hline & Present work & Gaudry et al. & Experimental \\
\hline $\mathrm{a}$ & 9.220 & - & 9.212 \\
$\mathrm{c}$ & 9.221 & - & 9.187 \\
$\mathrm{Al}-\mathrm{O}$ & 1.904 & 1.90 & 1.903 \\
$\mathrm{Al}-\mathrm{Be}$ & 2.662 & 2.66 & 2.66 \\
$\mathrm{Al}-\mathrm{Si}$ & 3.283 & 3.26 & 3.26 \\
\hline \hline
\end{tabular}

those found for ruby (Fig. 2), although $-(e) V_{R}(\mathbf{r}) \approx-70 \mathrm{eV}$ when we move along the $d_{2}$ direction approaching the $\mathrm{Be}^{2+}$ ion.

The influence of $V_{R}(\mathbf{r})$ upon the $10 \mathrm{Dq}$ value in emerald is shown in Fig. 3 where it is compared to the results found for ruby. In can be noticed that, in the absence of the electrostatic potential due to the rest of the lattice ions on the $\mathrm{CrO}_{6}{ }^{9-}$ complex, $10 \mathrm{Dq}$ would be the same for ruby and emerald. However, the changes in $10 \mathrm{Dq}$ due to $V_{R}(\mathbf{r})$ are very different in both gemstones, as shown in Fig. 3. In the case of emerald $V_{R}(\mathbf{r})$ induces a decrease of $56.413 \mathrm{eV}$ and $56.357 \mathrm{eV}$ on the energy of antibonding $e_{g}$ and $t_{2 g}$ levels, respectively. Therefore, this implies only a tiny reduction of $0.05 \mathrm{eV}$ on the $10 \mathrm{Dq}$ value calculated for the $\mathrm{CrO}_{6}{ }^{9-}$ complex in vacuo and thus a final 10Dq value equal to $1.95 \mathrm{eV}$. This value can be compared with the experimental figure for emerald, $10 \mathrm{Dq}=2.00 \mathrm{eV} .^{3,6}$

We have also verified that the changes of electronic density induced by the internal electric field are certainly smaller for emerald than for ruby. For instance, the average $3 d(\mathrm{Cr})$ population for the three $t_{2 g}$ levels is found to vary by $0.15 \%$ due to the addition of the internal electric field.

\section{STUDY OF A MODEL SYSTEM WITH CUBIC SYMMETRY}

\section{A. Description of the model}

A central question in this study is to determine the influence of electronic density changes induced by $\mathbf{E}_{R}(\mathbf{r})$ on the final $10 \mathrm{Dq}$ value. This relevant matter has been explored in the model system described in Fig. 6. In that system an octahedral

TABLE V. Values of Al-O, Al-Be, and Al-Si distances (all in angstroms) derived from the present periodic calculations for emerald $\left(\mathrm{Be}_{3} \mathrm{Si}_{6} \mathrm{Al}_{2} \mathrm{O}_{18}: \mathrm{Cr}^{3+}\right)$ and those previously obtained by Gaudry et al. ${ }^{13}$ by means of periodic Carr-Parinello calculations. The value of the $\mathrm{Cr}-\mathrm{O}$ distance measured by EXAFS (Ref. 13) is also included for comparison.

\begin{tabular}{lccc}
\hline \hline & Present work & Gaudry et al. & Experimental \\
\hline $\mathrm{Cr}-\mathrm{O}$ & 1.968 & 1.99 & $1.97 \pm 0.005$ \\
$\mathrm{Cr}-\mathrm{Be}$ & 2.695 & 2.70 & - \\
$\mathrm{Cr}-\mathrm{Si}$ & 3.306 & 3.31 & - \\
\hline \hline
\end{tabular}




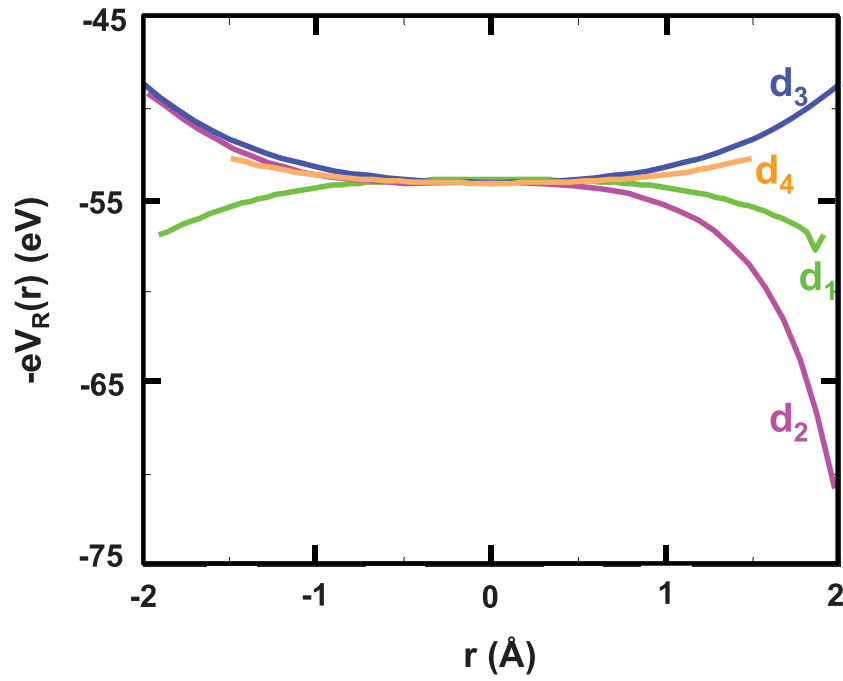

FIG. 5. (Color online) Potential energy $(-e) V_{R}(\mathbf{r})$ for emerald. Energy is depicted along $d_{1}, d_{2}, d_{3}$, and $d_{4}$ directions corresponding, respectively, to a $\mathrm{O}-\mathrm{Cr}-\mathrm{O}$ path joining two opposite oxygens, a $C_{2}$ axis joining $\mathrm{Cr}^{3+}$ with a close $\mathrm{Be}^{2+}$, the $C_{3}$ axis, and a path bisecting a $\mathrm{O}-\mathrm{Cr}-\mathrm{O}$ angle involving two adjacent oxygens which does not intersect a close $\mathrm{Be}^{2+}$ ion (Fig. 4).

$\mathrm{CrO}_{6}{ }^{9-}$ complex is surrounded by six identical point charges at the same distance $R_{q}$ from the chromium and placed along the three $C_{4}$ axes of the octahedron. In this model system such point charges create the internal electric field on the $\mathrm{CrO}_{6}{ }^{9-}$ unit but the octahedral symmetry is preserved. Particular attention has been paid to explore the variation of $10 \mathrm{Dq}$ as a function of the charge $\mathrm{Q}$ of the external point ion.

Although upon the addition of $V_{R}(\mathbf{r})$ the octahedral symmetry is kept, it modifies, however, the form of orbitals and its

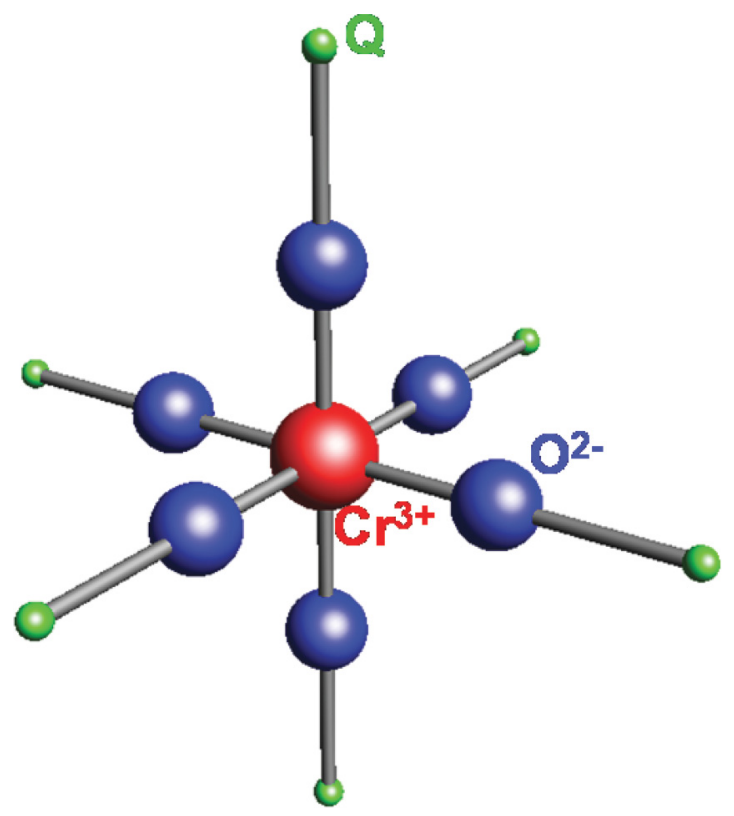

FIG. 6. (Color online) Model system formed by an octahedral $\mathrm{CrO}_{6}^{9-}$ complex surrounded by six identical point charges $Q$ at the same distance $R_{q}$ from the chromium ion and placed along the three $C_{4}$ axes of the octahedron. associated energy. Therefore the energy of a given orbital $\varepsilon_{n}$ can be written as

$$
\begin{gathered}
\varepsilon_{n}=\varepsilon_{n}^{0}+\varepsilon_{n}^{1}+\varepsilon_{n}^{2}+\cdots, \\
\varepsilon_{n}^{1}=\left\langle\phi_{n}^{0}\left|(-e) V_{R}\right| \phi_{n}^{0}\right\rangle ; \quad \varepsilon_{n}^{2}=\sum_{n^{\prime} \neq n} \frac{\left|\left\langle\phi_{n^{\prime}}^{0}\left|(-e) V_{R}\right| \phi_{n}^{0}\right\rangle\right|^{2}}{\varepsilon_{n}^{0}-\varepsilon_{n^{\prime}}^{0}} .
\end{gathered}
$$

Here $\phi_{n}^{0}$ and $\varepsilon_{n}^{0}$ mean the wave function and energy, respectively, corresponding to the $n$ orbital of the complex in the absence of the internal electric field. It is worth noting now that if $V_{R}(\mathbf{r})$ depends linearly on $Q$, then according to Eqs. (1) and (2), $\varepsilon_{n}^{1}$ and $\varepsilon_{n}^{2}$ scale like $Q$ and $Q^{2}$, respectively.

Similarly to what is written in Eq. (1), the changes in $10 \mathrm{Dq}$ due to $V_{R}(\mathbf{r})$ can shortly be written as

$$
10 \operatorname{Dq}(Q)=10 \mathrm{Dq}(0)+\Delta_{1}+\Delta_{2}+\cdots,
$$

where $10 \mathrm{Dq}(0)$ corresponds to the isolated complex, while $\Delta_{1}$ and $\Delta_{2}$ depend on $Q$ and $Q^{2}$, respectively. It should be noticed now that $\Delta_{1}$ reflects the $10 \mathrm{Dq}$ variation in first-order perturbation, which is derived using the frozen wave functions corresponding to $\mathbf{E}_{R}(\mathbf{r})=0$. By contrast, the correction called $\Delta_{2}$ does reflect the change of electronic density induced by the internal electric field.

In an isolated transition metal complex the antibonding $t_{2 g}$ and $e_{g}$ levels have the form ${ }^{24}$

$$
\begin{gathered}
\left|t_{2 g} ; r\right\rangle=\alpha_{t}\left|d\left(t_{2 g}\right) ; r\right\rangle-\beta_{p \pi}\left|\chi_{p \pi} ; r\right\rangle \quad(r=x y, x z, y z), \\
\left|e_{g} ; r\right\rangle=\alpha_{e}\left|d\left(e_{g}\right) ; r\right\rangle-\beta_{p \sigma}\left|\chi_{p \sigma} ; r\right\rangle-\beta_{s}\left|\chi_{s} ; r\right\rangle \\
\left(r=x^{2}-y^{2}, 3 z^{2}-r^{2}\right) .
\end{gathered}
$$

In Eq. (4) the first term on the right describes a pure $d$ wave function transforming like $x y, x z$, or $y z$, while the second term means a suitable linear combination of atomic orbitals (LCAO) involving $p_{\sigma}$ valence orbitals of six ligands. The coefficients $\alpha_{t}^{2}$ and $\beta_{p \pi}^{2}$ thus reflect the probability of finding the electron on the central cation and on ligands, respectively. In the case of the antibonding $e_{g}$ orbital, symmetry allows an admixture with valence $2 p_{\sigma}$ and $2 s$ orbitals if the ligands are oxygens. ${ }^{24}$

Let us now see what the changes of both $t_{2 g}$ and $e_{g}$ levels due to the addition of an internal field which keeps the cubic symmetry are. According to Eq. (2), if $V_{R}(\mathbf{r})$ also exhibits cubic symmetry, such orbitals can be mixed only with orbitals of the same label. So, the antibonding $t_{2 g}$ level can be mixed with the bonding counterpart called $t_{2 g}^{b}$, giving rise to changes in $\beta_{p \pi}$. Similarly, the antibonding $e_{g}$ level for the isolated complex mixes with the mainly $2 p_{\sigma}$ level called $e_{g}^{b}$, as well as with the mainly $2 s$ level denoted as $e_{g}^{s}$. This admixture leads to changes of $\beta_{p \sigma}$ and $\beta_{s}$ quantities when a nonconstant $V_{R}(\mathbf{r})$ potential on the complex is switched on.

Let us denote by $\beta_{p \sigma}(\mathbf{E}), \beta_{s}(\mathbf{E})$, or $\beta_{p \pi}(\mathbf{E})$ the molecular orbital coefficients associated with a given $\mathbf{E}_{R}(\mathbf{r})$. Obviously, if there is no electric field $\beta_{p \sigma}(0) \equiv \beta_{p \sigma}, \beta_{s}(0) \equiv \beta_{s}$ and $\beta_{p \pi}(\mathbf{0}) \equiv$ $\beta_{p \pi}$. Using second-order perturbation theory, the expression for $\Delta_{2}$ turns out to be

$$
\begin{aligned}
\Delta_{2}= & {\left[\beta_{p \sigma}(\boldsymbol{E})-\beta_{p \sigma}\right]^{2}\left[\varepsilon\left(e_{g}\right)-\varepsilon\left(e_{g}^{b}\right)\right] } \\
& +\left[\beta_{s}(\boldsymbol{E})-\beta_{s}\right]^{2}\left[\varepsilon\left(e_{g}\right)-\varepsilon\left(e_{g}^{s}\right)\right] \\
& +\left[\beta_{p \pi}(\boldsymbol{E})-\beta_{p \pi}\right]^{2}\left[\varepsilon\left(t_{2 g}\right)-\varepsilon\left(t_{2 g}^{b}\right)\right],
\end{aligned}
$$




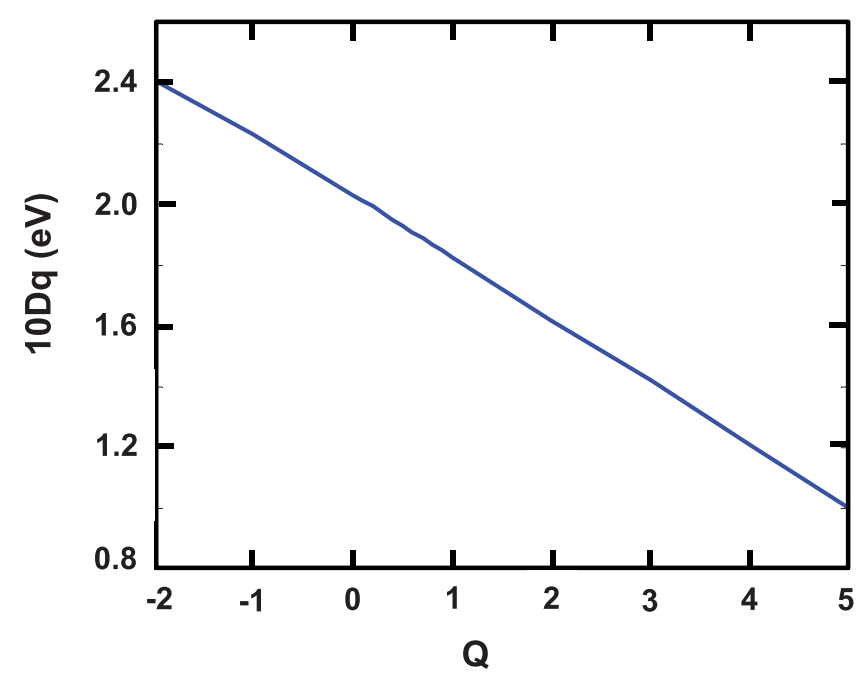

FIG. 7. (Color online) Calculated values of $10 \mathrm{Dq}$ as a function of the external charge $Q$ for the model system. The external charges are placed at a distance $R_{q}=4 \AA$ from the chromium ion.

where $\varepsilon\left(e_{g}\right), \varepsilon\left(t_{2 g}\right), \varepsilon\left(e_{g}^{b}\right), \varepsilon\left(e_{g}^{s}\right)$, or $\varepsilon\left(t_{2 g}^{b}\right)$ stand for orbital energies of the isolated complex. This expression allows one to estimate the value of $\Delta_{2}$ associated with a given internal field from the values of $\beta_{p \sigma}(\mathbf{E}), \beta_{s}(\mathbf{E})$, or $\beta_{p \pi}(\mathbf{E})$ and the orbital energies of the isolated complex derived from ab initio calculations.

\section{B. Results on the model system}

Calculated values of $10 \mathrm{Dq}$ as a function of the external charge $Q$ are portrayed in Fig. 7 where $Q$ is varied in the range between $-2 e$ and $5 e$. It can be noticed that the dependence of the calculated 10Dq upon $Q$ is essentially linear. Bearing in mind that the contributions $\Delta_{1}$ and $\Delta_{2}$ in Eq. (3) scale like $Q$ and $Q^{2}$, respectively, the results displayed in Fig. 7 already suggest that the changes in electronic density play a minor role for understanding the variations undergone by $10 \mathrm{Dq}$ due to the presence of the internal field. In other words, the changes are primarily due to first-order effects [reflected in Eq. (2)], thus involving only the frozen wave functions of the isolated complex.

Seeking to reinforce this view, we have estimated the $\Delta_{2}$ contribution by means of Eq. (6) and the values of $\beta_{p \sigma}(\mathbf{E})$, $\beta_{s}(\mathbf{E}), \beta_{p \pi}(\mathbf{E})$, and the involved excitations derived from the present calculations. In Table VI the values of 10Dq and the $\beta_{p \sigma}(\mathbf{E}), \beta_{s}(\mathbf{E}), \beta_{p \sigma}(\mathbf{E})$ parameters calculated for $Q=3 e$ are compared to those for the complex in vacuo $(Q=0)$. For estimating the second-order contribution $\Delta_{2}$, we have used the values $\varepsilon\left(e_{g}\right)-\varepsilon\left(e_{g}^{b}\right)=8.2 \mathrm{eV}, \varepsilon\left(t_{2 g}\right)-\varepsilon\left(t_{2 g}^{b}\right)=6.4 \mathrm{eV}$, and $\varepsilon\left(e_{g}\right)-\varepsilon\left(e_{g}^{s}\right)=21 \mathrm{eV}$ derived from the present calculations for $Q=0$.

It can be remarked in Table VI that on passing from the complex in vacuo to $Q=3 e$, the value of $10 \mathrm{Dq}$ decreases by $0.6 \mathrm{eV}$, while $\Delta_{2}$ is estimated to be one order of magnitude lower. Bearing in mind that $10 \mathrm{Dq}(Q)-10 \mathrm{Dq}(0)$ for $Q=3 e$ is four times bigger in the model system than for ruby, it is thus reasonable to accept that in all these cases the changes
TABLE VI. Values of 10Dq (in electronvolts) and the covalency parameters $\alpha_{e}^{2}(\mathbf{E}), \alpha_{t}^{2}(\mathbf{E}), \beta_{p \sigma}^{2}(\mathbf{E}), \beta_{p \pi}^{2}(\mathbf{E})$, and $\beta_{s}^{2}(\mathbf{E})$ (in percent) calculated for the model system formed by the $\mathrm{CrO}_{6}^{9-}$ complex and six point charges $Q$ keeping the octahedral symmetry. The results obtained for $Q=3 e$ are compared to those derived for the isolated complex $(Q=0)$. The value of the contribution to $10 \mathrm{Dq}$ called $\Delta_{2}$ (in electronvolts) is estimated by means of Eq. (6) and the calculated values of $\beta_{i}^{2}(\mathbf{E})$ parameters.

\begin{tabular}{lccccccc}
\hline \hline & $10 \mathrm{Dq}$ & $\alpha_{e}^{2}(\mathbf{E})$ & $\alpha_{t}^{2}(\mathbf{E})$ & $\beta_{p \sigma}^{2}(\mathbf{E})$ & $\beta_{p \pi}^{2}(\mathbf{E})$ & $\beta_{s}^{2}(\mathbf{E})$ & $\Delta_{2}$ \\
\hline$Q=0$ & 2.03 & 77.3 & 87.5 & 18.5 & 10.9 & 2.9 & 0 \\
$Q=3 e$ & 1.42 & 82.0 & 86.0 & 10.7 & 13.3 & 5.0 & 0.08 \\
\hline \hline
\end{tabular}

in $10 \mathrm{Dq}$ are governed by the $\Delta_{1}$ contribution where only the frozen wave functions of the isolated complex are involved.

On Fig. 8 the form of $(-e) V_{R}(\mathbf{r})$ along $\langle 100\rangle$ and $\langle 110\rangle$ directions is depicted. It can be noted that, as expected, when $\mathbf{r}$ is parallel to $\langle 100\rangle$ then $(-e) V_{R}(\mathbf{r})<(-e) V_{R}(0)$ and thus the electrons which are close to ligands experience a supplementary electrostatic attraction. Let us now consider an $\mathrm{e}_{\mathrm{g}}$ level where the electronic charge is lying mainly along $\langle 100\rangle$ directions. Therefore, if we designate by $\left|e_{g}^{0}\right\rangle$ the wave function of such a level for $Q=0$, then, according to Fig. 8 the quantity $\left\langle e_{g}^{0}\left|(-e) V_{R}\right| e_{g}^{0}\right\rangle$ tends to decrease the energy of the $e_{g}$ level. On the contrary, $(-e) V_{R}(\mathbf{r})$ along $\langle 110\rangle$ directions increases slightly when $|\mathbf{r}|$ does. This result is consistent with the form of an electrostatic potential $V_{R}(\mathbf{r})$ in cubic symmetry: ${ }^{24}$

$$
V_{R}(\mathbf{r})=A\left(x^{4}+y+z^{4}-\frac{3}{5} r^{4}\right)+\cdots .
$$

As in the $t_{2 g}$ level, if the wave functions are pointing at $\langle 110\rangle$ directions, then the quantity $\left\langle t_{2 g}^{0}\left|(-e) V_{R}\right| t_{2 g}^{0}\right\rangle$ increases the energy of such a level. Therefore, in accordance with this reasoning, the electric field reflected in Fig. 8 tends to reduce the $10 \mathrm{Dq}$ value. This explains, albeit qualitatively, the results displayed in Table VI.

It is worth noting now that the addition of $V_{R}(\mathbf{r})$ increases the value of $\alpha_{\mathrm{e}}^{2}$ corresponding to the antibonding $e_{g}$ level

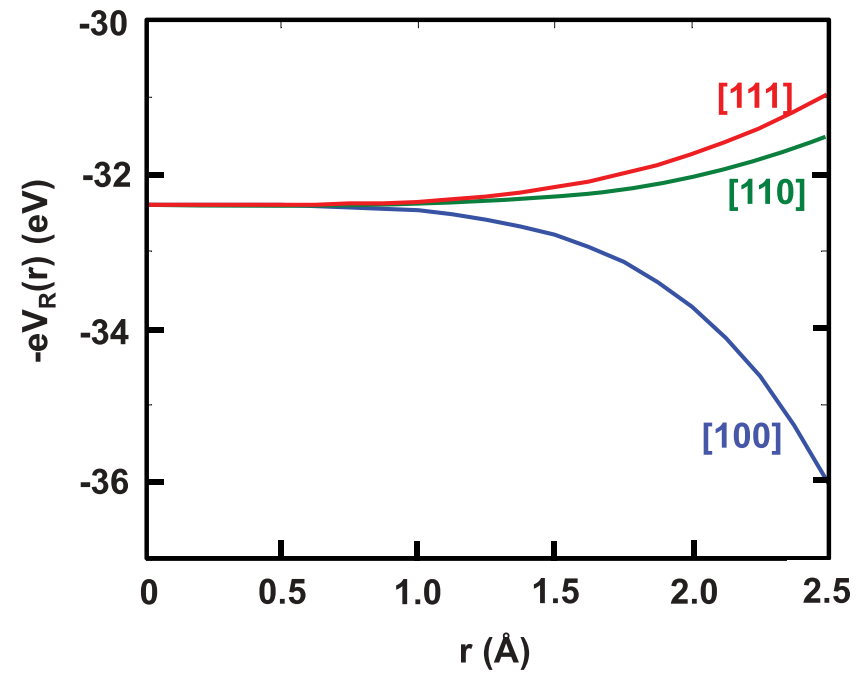

FIG. 8. (Color online) Form of $(-e) V_{R}(\mathbf{r})$ along $\langle 100\rangle$ and $\langle 110\rangle$ directions in the octahedral model system. 
(Table VI), while the opposite happens for the fully occupied $e_{g}^{b}$ level. This gives rise again to a net flow of the electronic charge from central ion to ligands consistent with the form of $(-e) V_{R}(\mathbf{r})$ along the $\langle 100\rangle$ directions depicted in Fig. 8.

Following the present analysis, if we rotate the four $Q$ charges lying in the $X Y$ plane by an angle $\theta=45^{\circ}$ it can be expected that this new potential decreases the energy of the $x y$ orbital while increasing that corresponding to the $x^{2}-y^{2}$ orbital. Despite that this new potential has a tetragonal symmetry, we have verified that it increases the separation between $x y$ and $x^{2}-y^{2}$ orbitals and the 10Dq value.

\section{Application to gemstones}

The analysis carried out in the foregoing section strongly supports that the change in $10 \mathrm{Dq}$ in ruby is essentially related neither to the polarization of the chromium ion nor to the polarization change on ligands induced by the internal electric field. In fact, both phenomena do involve a change of electronic density, while we have shown that these effects play a secondary role for understanding the changes due to $\mathbf{E}_{R}(\mathbf{r})$. The present analysis points out that the changes in $10 \mathrm{Dq}$ arise from the different form of $V_{R}(\mathbf{r})$ along different directions keeping the electronic density of the isolated complex. In the case of ruby the form of $V_{R}(\mathbf{r})$ along $d_{2}$ and $d_{3}$ directions (Fig. 2) is not symmetric around $\mathbf{r}=0$, and $(-e)\left\{V_{R}\left(\mathbf{r}-V_{R}(\mathbf{0})\right\}\right.$ $<0$ when we approach a close aluminum ion. Bearing in mind that $t_{2 g}$ orbitals are lying mainly along such directions, ${ }^{17}$ the action of $(-e) V_{R}(\mathbf{r})$ tends to decrease the energy of such orbitals. By contrast, the variation of $V_{R}(\mathbf{r})$ along metal-ligand directions is more symmetric and much softer than for $d_{2}$ and $d_{3}$ directions. Therefore, it can reasonably be expected that $V_{R}(\mathbf{r})$ induces a bigger decrease for $t_{2 g}$ orbitals than for $e_{g}$ ones lying along metal-ligand directions. This explains albeit qualitatively the increase of $10 \mathrm{Dq}$ due to the internal field in the case of ruby (Fig. 3).

In the case of emerald (Fig. 5), the quantity $\left|V_{R}(\mathbf{r})-V_{R}(\mathbf{0})\right|$ is in general smaller than that obtained for ruby. Nevertheless, it is comparable to that found for the model system (Fig. 8). Despite this fact the internal field only produces a little variation on $10 \mathrm{Dq}$ in the case of emerald. If we look at $d_{2}$, $d_{3}$, and $d_{4}$ directions where $t_{2 g}$ orbitals are lying, we see that the effect of $V_{R}(\mathbf{r})$ is not homogeneous. For instance, it tends to raise the orbital energy for $d_{3}$ and $d_{4}$ directions while when the electron approaches a close $\mathrm{Be}^{2+}$ such energy decreases. This suggests the existence of a compensation mechanism behind the actual $10 \mathrm{Dq}$ value for emerald.

For clarifying this matter we have calculated the $10 \mathrm{Dq}$ value of the emerald including in $V_{R}(\mathbf{r})$ only the electrostatic potential coming from the nearest $\mathrm{Be}^{2+}$ ions. In a second step we have also included in the calculation the electrostatic potential arising from the six nearest $\mathrm{Si}^{4+}$ ions. These results, gathered in Table VII, are compared to those obtained including in $V_{R}(\mathbf{r})$ all ions lying outside the $\mathrm{CrO}_{6}^{9-}$ complex. It can be noticed that if only the nearest $\mathrm{Be}^{2+}$ ions are considered when calculating $V_{R}(\mathbf{r})$, it leads to $10 \mathrm{Dq}=2.20 \mathrm{eV}$, which is $10 \%$ higher than the value obtained for the isolated $\mathrm{CrO}_{6}^{9-}$ unit at $R=1.97 \AA$. By contrast, when the next shell involving six $\mathrm{Si}^{4+}$ ions at $3.31 \AA$ from $\mathrm{Cr}^{3+}$ is also taken into account, then the value $10 \mathrm{Dq}=1.93 \mathrm{eV}$ is practically coincident with
TABLE VII. Calculated 10Dq values (in electronvolts) for the emerald with four different representations of $V_{R}(\mathbf{r})$ : (a) $V_{R}(\mathbf{r})=0$ (isolated complex); (b) including only the first shell of three $\mathrm{Be}^{2+}$ ions lying outside the $\mathrm{CrO}_{6}^{9-}$ complex; (c) including the first and also the second shell composed by six $\mathrm{Si}^{4+}$ ions; and (d) including in $V_{R}(\mathbf{r})$ all ions lying outside the $\mathrm{CrO}_{6}^{9-}$ complex. In all cases the $\mathrm{Cr}^{3+}-\mathrm{O}^{2-}$ distance is $R=1.97 \AA$.

\begin{tabular}{ll}
\hline \hline System & $10 \mathrm{Dq}$ \\
\hline Isolated $\mathrm{CrO}_{6}^{9-}$ unit & 2.007 \\
$\mathrm{CrO}_{6}^{9-}+3 \mathrm{Be}^{2+}$ & 2.200 \\
$\mathrm{CrO}_{6}^{9-}+3 \mathrm{Be}^{2+}+6 \mathrm{Si}^{4+}$ & 1.933 \\
$\mathrm{CrO}_{6}^{9-}+$ all lattice charges & 1.951 \\
\hline \hline
\end{tabular}

the figure $10 \mathrm{Dq}=1.95 \mathrm{eV}$ obtained including in $V_{R}(\mathbf{r})$ all ions lying outside the $\mathrm{CrO}_{6}^{9-}$ complex. On one hand, this fact stresses that the quantity $V_{R}(\mathbf{r})-V_{R}(\mathbf{0})$ governing $10 \mathrm{Dq}$ mainly depends on the first shells around the complex. In other words, although all ions are contributing to $V_{R}(\mathbf{0})$, nevertheless $V_{R}(\mathbf{r})-V_{R}(\mathbf{0})$ and $\Delta_{1}$ are essentially reproduced considering only a few shells of ions around the complex. ${ }^{32,60}$ On the other hand, it proves that the very small changes induced by $V_{R}(\mathbf{r})$ on the $10 \mathrm{Dq}$ value in emerald is the result of a practical cancellation of the contribution due to the three $\mathrm{Be}^{2+}$ ions at $2.66 \AA$ by that coming from six $\mathrm{Si}^{4+}$ ions at $3.31 \AA$. This finding has some similarities with the near independence of 10Dq upon $V_{R}(\mathbf{r})$ in the case of perovskites like $\mathrm{KMgF}_{3}$ doped with $\mathrm{Mn}^{2+}$ or $\mathrm{Ni}^{2+} .32$ In such a case this behavior comes from the cancellation of the contribution to $10 \mathrm{Dq}$ due to the first shell of eight $\mathrm{K}^{+}$ions by that of the second shell involving six $\mathrm{Mg}^{2+}$ ions. By contrast, a different situation holds for the inverse perovskite $\mathrm{LiBaF}_{3}$ doped with divalent impurities where $\Delta_{1}$ arises mainly from the first shell made by eight $\mathrm{Ba}^{2+}$ ions. $^{32}$

\section{FINAL REMARKS}

The present results stress the relevance of internal fields for a good understanding of optical and magnetic properties of transition-metal impurities in insulators. This situation thus has some connections with the interpretation of the quadrupole splitting on a given nucleus placed in a noncubic site, observed either in Mossbauer spectroscopy ${ }^{61}$ or through magnetic resonance techniques. ${ }^{62}$ Indeed, a right understanding of such splitting requires calculation of the quantities $\left(\partial^{2} V / \partial x_{i}^{2}\right)_{0}$ at the nucleus site $\left(x_{i}=0\right)$, where $V\left(x_{i}\right)$ just means the electrostatic potential around the nucleus due to the rest of nuclei and the electronic charge. ${ }^{63}$

The results and analysis carried out in this work confirm that the different color exhibited by $\mathrm{Cr}^{3+}$ gemstones is due neither to differences in the mean $\mathrm{Cr}^{3+}-\mathrm{O}^{2-}$ distance nor to the flow of unpaired electrons outside the $\mathrm{CrO}_{6}^{9-}$ unit. By contrast, the small changes in $10 \mathrm{Dq}$ and the color shift in the series of ionic oxides doped with $\mathrm{Cr}^{3+}$ can reasonably be understood considering only the $\mathrm{CrO}_{6}^{9-}$ unit and the internal field $\mathbf{E}_{R}(\mathbf{r})$ created by the rest of lattice ions upon the localized electrons. This result thus concurs with a previous study showing that the separation $\Delta\left({ }^{4} T_{1} ;{ }^{4} T_{2}\right)$ between ${ }^{4} T_{2}\left(t_{2 g}^{2} e_{g}^{1}\right)$ and ${ }^{4} T_{1}\left(t_{2 g}^{2} e_{g}^{1}\right)$ 
states as well as the energy $E\left({ }^{2} E\right)$ of the ${ }^{2} E\left(t_{2 g}^{3}\right) \rightarrow{ }^{4} A_{2}\left(t_{2 g}^{3}\right)$ emission transition of $\mathrm{Cr}^{3+}$ in different lattices can be well accounted for on the same grounds. ${ }^{34}$

As a salient feature the present study demonstrates quantitatively that the modifications of electronic density due to the internal field do not play a relevant role for understanding the changes induced on the ${ }^{4} A_{2}\left(t_{2 g}^{3}\right) \rightarrow{ }^{4} T_{2}\left(t_{2 g}^{2} e_{g}^{1}\right)$ transition and thus the color of the gemstone. Therefore, although $\mathbf{E}_{R}(\mathbf{r})$ modifies the covalency in the $\mathrm{CrO}_{6}^{9-}$ unit, this small change is not the main factor responsible for the different 10Dq exhibited by ruby and emerald, a conclusion which is against previous assumptions. ${ }^{11,64}$

Although $10 \mathrm{Dq}$ can be understood by merely taking into account first-order effects induced by the internal field, this is no longer true for other quantities like $\Delta\left({ }^{4} T_{1} ;{ }^{4} T_{2}\right)$, which are nearly independent of 10Dq. Indeed the variations of this quantity along the series of oxides or fluorides have been shown to reflect the changes induced by the internal field on the electronic density. ${ }^{34}$

It is worth noting now the similarities between the present problem and the static Jahn-Teller effect taking place, for instance, for $d^{9}$ ions under an initial coordination which is perfectly octahedral. In such cases the values of axial and equatorial metal-ligand distances of the equilibrium tetragonal geometry and the involved Jahn-Teller energy, $E_{\mathrm{JT}}$, can also be understood only through the frozen wave functions corresponding to the initial high-symmetry configuration. By contrast, the barrier among equivalent distorted configurations partially depends on the electronic density change induced by the distortion. ${ }^{65}$

Despite the fact that all ions outside the $\mathrm{CrO}_{6}^{9-}$ unit contribute to the electrostatic potential at the chromium site $V_{R}(\mathbf{0})$, it has been emphasized through this work that the variations on $10 \mathrm{Dq}$ come from the quantity $V_{R}(\mathbf{r})-V_{R}(\mathbf{0})$, which is essentially reproduced through the first shells of ions around the complex. A similar conclusion was reached in a previous study on the color shift along the series of $\mathrm{Al}_{2-x} \mathrm{Cr}_{x} \mathrm{O}_{3}$ mixed crystals. ${ }^{60}$

Bearing in mind the present study, it is tempting to try to explain why the 10Dq value measured for $\mathrm{MgO}: \mathrm{Cr}^{3+}$ (Ref. 66) is coincident with that of emerald. As the $\mathrm{Mg}^{2+}-\mathrm{O}^{2-}$ distance in $\mathrm{MgO}$ is $2.10 \AA$, it is hard to accept that the $\mathrm{Cr}^{3+}-\mathrm{O}^{2-}$ distance in $\mathrm{MgO}: \mathrm{Cr}^{3+}$ is the same as in emerald. Work along this line is now underway.

\section{ACKNOWLEDGMENTS}

Support from the Spanish Ministerio de Ciencia y Tecnología under Project No. FIS2009-07083 is acknowledged.
${ }^{1}$ L. E. Orgel, Nature (London) 179, 1348 (1957).

${ }^{2}$ D. Reinen, Struct. Bonding 6, 30 (1969).

${ }^{3} \mathrm{~K}$. Nassau, The Physics and Chemistry of Colour (John Wiley \& Sons, New York, 1983).

${ }^{4}$ R. Reisfeld and C. K. Jørgensen, Struct. Bonding 69, 63 (1988).

${ }^{5}$ S. J. Duclos, Y. K. Vohra, and A. L. Ruoff, Phys. Rev. B 41, 5372 (1990).

${ }^{6}$ R. G. Burns, Mineralogical Applications of Crystal Field Theory (Cambridge University Press, Cambridge, 1993).

${ }^{7}$ J. Simmons and K. S. Potter, Optical Materials (Academic Press, New York, 2000).

${ }^{8}$ T. H. Yeom and S. H. Choh, J. Appl. Phys. 90, 5946 (2001).

${ }^{9}$ E. Gaudry, A. Kiratisin, P. Sainctavit, C. Brouder, F. Mauri, A. Ramos, A. Rogalev, and J. Goulon, Phys. Rev. B 67, 094108 (2003).

${ }^{10}$ V. S. Urusov and M. N. Taran, Phys. Chem. Miner. 39, 17 (2012).

${ }^{11}$ J. M. Garcia-Lastra, M. T. Barriuso, J. A. Aramburu, and M. Moreno, Phys. Rev. B 72, 113104 (2005).

${ }^{12}$ J. M. Garcia-Lastra, J. A. Aramburu, M. T. Barriuso, and M. Moreno, Phys. Rev. B 74, 115118 (2006).

${ }^{13}$ E. Gaudry, D. Cabaret, C. Brouder, I. Letard, A. Rogalev, F. Wilhlem, N. Jaouen, and P. Sainctavit, Phys. Rev. B 76, 094110 (2007).

${ }^{14}$ A. Juhin, G. Calas, D. Cabaret, L. Galoisy, and J.-L. Hazemann, Phys. Rev. B 76, 054105 (2007).

${ }^{15}$ R. J. D. Tilley, Defects in Solids (John Wiley \& Sons, New York, 2008).

${ }^{16}$ K. Krambrock, K. J. Guedes, and M. Pinheiro, Phys. Chem. Miner. 35, 409 (2008).

${ }^{17}$ J. M. Garcia-Lastra, M. T. Barriuso, J. A. Aramburu, and M. Moreno, Phys. Rev. B 78, 085117 (2008).
${ }^{18}$ S. Watanabe, T. Sasaki, R. Taniguchi, T. Ishii, and K. Ogasawara, Phys. Rev. B 79, 075109 (2009).

${ }^{19}$ G. Cruciani, M. Ardit, M. Dondi, F. Matteucci, M. Blosi, M. Dalconi, and S. Albonetti, J. Phys. Chem. A 113, 13772 (2009).

${ }^{20}$ F. Farges, Phys. Chem. Miner. 36, 463 (2009).

${ }^{21}$ U. Halenius, G. B. Andreozzi, and H. Skogby, Am. Mineral. 95, 456 (2010).

${ }^{22}$ B. D. Fahlman, Materials Chemistry (Springer, Dordrecht, 2011).

${ }^{23}$ M. Andrut, M. Wildner, and C. Z. Rudowicz, in Optical Absorption Spectroscopy in Geosciences. Part II: Quantitative Aspects of Crystal Fields, edited by A. Beran and E. Libowitzky, EMU Notes in Mineralogy, Vol. 6 (University Press, Budapest, 2004), p. 145.

${ }^{24}$ S. Sugano, Y. Tanabe, and H. Kamimura, in Multiplets of TransitionMetal Ions in Crystals (Academic Press, New York, 1970), p. 331.

${ }^{25}$ H. G. Drickamer and C. W. Frank, Electronic Transitions and the High Pressure Chemistry of Solids (Chapman Hall, London, 1973).

${ }^{26}$ M. Moreno, M. T. Barriuso, J. A. Aramburu, P. Garcia-Fernandez, and J. M. Garcia-Lastra, J. Phys. Condens. Matter 18, R315 (2006).

${ }^{27}$ D. L. Wood, J. Ferguson, K. Knox, and J. F. Dillon, J. Chem. Phys. 39, 890 (1963).

${ }^{28}$ D. Reinen, M. Atanasov, and S. L. Lee, Coord. Chem. Rev. 175, 91 (1998).

${ }^{29}$ H. Thauern and R. Glaum, Inorg. Chem. 46, 2057 (2007).

${ }^{30}$ N. Laurance, E. C. McIrvine, and J. Lambe, J. Phys. Chem. Solids 23, 515 (1962).

${ }^{31}$ D. Bravo and R. Bottcher, J. Phys. Condens. Matter 4, 7295 (1992).

${ }^{32}$ A. Trueba, J. M. García-Lastra, M. T. Barriuso, J. A. Aramburu, and M. Moreno, Phys. Rev. B 78, 075108 (2008).

${ }^{33}$ J. M. García-Lastra, M. T. Barriuso, J. A. Aramburu, and M. Moreno, J. Phys. Condens. Matter 22, 155502 (2010). 
${ }^{34}$ A. Trueba, J. M. García-Lastra, P. Garcia-Fernandez, M. T. Barriuso, J. A. Aramburu, and M. Moreno, J. Phys. Chem. A 115, 13399 (2011).

${ }^{35}$ R. C. Powell, Physics of Solid State Laser Materials (Springer, New York, 1998).

${ }^{36}$ R. W. G. Wyckoff, Crystal Structures, Vol. 1 (John Wiley \& Sons, New York, 1963).

${ }^{37}$ G. V. Gibbs, D. W. Breck, and E. P. Meagher, Lithos 1, 275 (1968).

${ }^{38}$ B. Morosin, Acta Crystallogr. B 28, 1899 (1972).

${ }^{39}$ J. M. García-Lastra, J. A. Aramburu, M. T. Barriuso, and M. Moreno, Phys. Rev. Lett. 93, 226402 (2004); Chem. Phys. Lett. 385, 286 (2004)

${ }^{40}$ R. G. Parr and W. Yang, Density-Functional Theory of Atoms and Molecules (Oxford University Press, New York, 1989).

${ }^{41}$ W. Kohn, Phys. Rev. A 133, 171 (1965).

${ }^{42}$ W. Kohn, Phys. Rev. Lett. 76, 3168 (1996).

${ }^{43}$ R. Resta, J. Phys. Condens. Matter 14, R625 (2002).

${ }^{44}$ R. K. Jeck and J. J. Krebs, Phys. Rev. B 5, 1677 (1972).

${ }^{45}$ J. A. Weil, J. R. Bolton, and J. E. Werz, Electron Paramagnetic Resonance (Wiley, New York, 1994).

${ }^{46}$ P. Studzinski and J. M. Spaeth, Phys. Status Solidi B 136, 735 (1986).

${ }^{47}$ R. Dovesi, R. Orlando, B. Civalleri, C. Roetti, V. R. Saunders, and C. M. Zicovich-Wilson, Kristallogr. 220, 571 (2005).

${ }^{48}$ CRYSTAL basis sets, http://www.crystal.unito.it/Basis_Sets/Ptable. html.

${ }^{49}$ D. I. Bilc, R. Orlando, R. Shaltaf, G.-M. Rignanese, J. Iñiguez, and Ph. Ghosez, Phys. Rev. B 77, 165107 (2008).

${ }^{50}$ G. te Velde, F. M. Bickelhaupt, E. J. Baerends, C. F. Guerra, S. J. A. van Gisbergen, J. G. Snijders, and T. Ziegler, J. Comput. Chem. 22, 931 (2001).
${ }^{51}$ J. P. Perdew, in Electronic Structure of Solids' 91, edited by P. Ziesche and H. Eschrig (Akademie Verlag, Berlin, 1991), p. 11.

${ }^{52}$ J. A. Aramburu, J. M. García-Lastra, M. T. Barriuso, and M. Moreno, Int. J. Quantum Chem. 91, 197 (2003).

${ }^{53}$ N. Lopez and F. J. Illas, J. Phys. Chem. B 1021430 (1998).

${ }^{54}$ M. T. Barriuso, J. A. Aramburu, and M. Moreno, J. Phys. Condens. Matter 11, L525 (1999).

${ }^{55}$ M. Atanasov, C. A. Daul, and C. Rauzy, Chem. Phys. Lett. 367, 737 (2003).

${ }^{56}$ J. A. Aramburu, M. Moreno, K. Doclo, C. Daul, and M. T. Barriuso, J. Chem. Phys. 110, 1497 (1999).

${ }^{57}$ C. Sousa, C. de Graaf, and F. Illas, Phys. Rev. B 62, 10013 (2000).

${ }^{58}$ W. Duan, G. Paiva, R. M. Wentzcovitch, and A. Fazzio, Phys. Rev. Lett. 81, 3267 (1998).

${ }^{59}$ V. V. Mazurenko, A. N. Varaksin, V. G. Mazurenko, V. S. Kortov, and V. I. Anisimov, Physica B 344, 385 (2004).

${ }^{60}$ J. M. García-Lastra, M. T. Barriuso, J. A. Aramburu, and M. Moreno, Phys. Rev. B 79, 241106(R) (2009).

${ }^{61}$ A. Vertes, L. Korecz, and K. Burger, in Mössbauer Spectroscopy (Elsevier, Amsterdam, 1979), p. 40.

${ }^{62} \mathrm{~A}$. Abragam and B. Bleaney, in Electron Paramagnetic Resonance of Transition Ions (Clarendon Press, Oxford, 1970), p. 414.

${ }^{63}$ P. Blaha, K. Schwarz, W. Faber, and J. Luitz, Hyperfine Interact. 126, 389 (2000).

${ }^{64}$ N. Wiberg, A. F. Holleman, and E. Wiberg, in Inorganic Chemistry (Academic Press, San Diego, CA, 2001), p. 1198.

${ }^{65}$ P. García-Fernández, I. B. Bersuker, J. A. Aramburu, M. T. Barriuso, and M. Moreno, Phys. Rev. B 71, 184117 (2005).

${ }^{66}$ S. Kück, L. Fornasiero, E. Heumann, E. Mix, G. Huber, T. Kärner, and A. Maaroos, Laser Phys. 10, 411 (2000). 